\title{
Sensory evaluation of ice creams prepared with different inclusion levels of Jackfruit pulp
}

\author{
N.E. Safia and S. Simi
}

Received: 28.09.2019; Revised: 03.11.2019; Accepted: 17.11.2019

See end of the paper for authors' affiliations

\section{N.E. Safia}

ICAR- Krishi Vigyan Kendra

(K.A.U.), Ambalavayal,

Wayanad (Kerala) India

Email : safiya.ne@kau.in
ABSTRACT : Ice-cream, a highly popular frozen dairy product is liked by persons of all age group. Fruit-flavoured ice creams rank third among flavours, representing about 8 per cent of the total amount of ice cream made, and can be consumed more or less throughout the year. The excellent nutritional profile and multifunctional properties of Jackfruit can be utilized in the preparation of ice cream, rich in nutrients and having unique distinct flavour and colour. Keeping in front the consumers demand for ice-cream with natural ingredients and nutritional importance, this study was designed primarily to examine the acceptable organoleptic characteristics of icecream incorporating jackfruit. The present study was undertaken with different combinations $(15 \%, 20 \%$ and $25 \%)$ of jackfruit pulp in ice cream preparation. Different samples of jackfruit icecream treatments and control were analyzed for organoleptic characteristics like flavour and taste, body texture, colour and appearance, melting quality and overall acceptability. Sensory evaluation was carried out using 9-point hedonic scale Amerine et al. (1965). The data obtained on various parameters were statistically analysed. In terms of body and texture $15 \%\left(\mathrm{~T}_{2}\right)$ jackfruit was highly acceptable followed by the sample containing $20 \%\left(\mathrm{~T}_{3}\right)$ of jackfruit pulp. The colour and appearance scores increase with increase in the jackfruit pulp in the blend. The flavor scores increases first with increase in the jackfruit pulp in the blend but tended to decrease later with increase in jackfruit pulp in the blend. The highest melting quality was noted in sample containing $15 \%\left(\mathrm{~T}_{2}\right)$ and $20 \%\left(\mathrm{~T}_{3}\right)$ of jackfruit pulp in the blend. The overall acceptability scores of ice cream tended to decrease with increase in the jackfruit pulp in blend. A progressive deterioration was observed in all sensory parameters with ice cream samples prepared with $25 \%\left(\mathrm{~T}_{4}\right)$ of jackfruit pulp. The results of this study may be useful for ice cream manufacturers and the information may be used to produce ice cream with increased consumer liking.

KEY WORDS: Jackfruit, Ice-cream, Organoleptic characteristics, Consumer preference

- HOW TO CITE THIS PAPER : Safia, N.E. and Simi, S. (2019). Sensory evaluation of ice creams prepared with different inclusion levels of Jackfruit pulp. Asian J. Home Sci., 14 (2) : 411-414, DOI: 10.15740/HAS/AJHS/14.2/411-414. Copyright@ 2019: Hind Agri-Horticultural Society. 